\title{
Differentiation of Recurrent Tumor and Posttreatment Changes in Head and Neck Squamous Cell Carcinoma: Application of High b-Value Diffusion-Weighted Imaging
}

\author{
I. Hwang, S.H. Choi, Y.-J. Kim, K.G. Kim, A.L. Lee, T.J. Yun, J.-h. Kim, and C.-H. Sohn
}

\begin{abstract}
BACKGROUND AND PURPOSE: High b-value DWI has been expected to have an additional diagnostic role and demonstrated some promising results in head and neck cancer. The aim of this study was to evaluate the diagnostic performance of DWI at a high $b$-value $\left(b=2000 \mathrm{~s} / \mathrm{mm}^{2}\right)$ compared with a standard b-value $\left(b=1000 \mathrm{~s} / \mathrm{mm}^{2}\right)$ and the ratio of ADC values of high and standard b-values for their ability to differentiate between recurrent tumor and posttreatment changes after the treatment of head and neck squamous cell carcinoma.
\end{abstract}

MATERIALS AND METHODS: A total of 33 patients diagnosed with head and neck squamous cell carcinoma were enrolled in the present study; all had contrast-enhancing lesions on follow-up MR imaging. All patients underwent single-shot echo-planar DWI at $b=1000 \mathrm{~s} / \mathrm{mm}^{2}$ and $b=2000 \mathrm{~s} / \mathrm{mm}^{2}$, and corresponding $A D C$ maps were generated ( $A D C_{1000}$ and $A D C_{2000}$, respectively). The mean $A D C_{1000}, A D C_{2000}$, and $A D C_{\text {ratio }}\left(A D C_{\text {ratio }}=A D C_{2000} / A D C_{1000} \times 100\right)$ values were evaluated within a manually placed $R O$ l with contrast-enhanced T1-weighted images as references. For the statistical analysis, we performed a Student $t$ test and multivariate logistic regression.

RESULTS: The mean $\mathrm{ADC}_{1000}$ in recurrent tumor was significantly lower than that in posttreatment changes $(P<.001)$, whereas the mean $A D C_{2000}$ resulted in no significant difference $(P=.365)$. The mean $A D C_{\text {ratio }}$ was significantly higher in recurrent tumor than that in posttreatment changes $(73.5 \pm 7.2 \%$ vs $56.9 \pm 8.8 \%$, respectively; $P<.001)$. Multivariate logistic regression analysis revealed that the $A D C_{\text {ratio }}$ was the only independently differentiating variable $(P=.024)$. The sensitivity, specificity, and accuracy of $A D C_{\text {ratio }}$ were $95.0 \%$, $69.2 \%$, and $84.8 \%$, respectively, by use of the optimal cutoff value of $62.6 \%$.

CONCLUSIONS: We suggest that the $A D C_{\text {ratio }}$ calculated from the $A D C_{1000}$ and $A D C_{2000}$ is a promising value for the differentiation of recurrent tumor and posttreatment changes in head and neck squamous cell carcinoma.

ABBREVIATIONS: $A \mathrm{ADC}_{1000}=\mathrm{ADC}$ value calculated at $b=0$ and $1000 \mathrm{~s} / \mathrm{mm}^{2} ; \mathrm{ADC}_{2000}=\mathrm{ADC}$ value calculated at $b=0$ and $2000 \mathrm{~s} / \mathrm{mm}^{2} ; \mathrm{ADC}_{\text {ratio }}=$ ratio of $\mathrm{ADC} C_{2000}$ over $\mathrm{ADC}_{1000}$; $\mathrm{HNSCC}=$ head and neck squamous cell carcinoma

maging surveillance after treatment of head and neck squamous cell carcinoma (HNSCC) is useful to detect residual or recurrent tumor, even when clinical recurrence is not suspected. In these patients, however, the multidisciplinary treatment with surgery, radiation therapy, and/or chemotherapy that improves pa-

Received January 17, 2013; accepted after revision March 19.

From the Department of Radiology (I.H., S.H.C., A.L.L., T.J.Y., J.-h.K., C.-H.S.) Seoul National University College of Medicine, Seoul, Korea; Center for Nanoparticle Research (S.H.C.), Institute for Basic Science, and School of Chemical and Biological Engineering, Seoul National University, Seoul, Korea; and Biomedical Engineering Branch (Y.-J.K., K.G.K.), Division of Convergence Technology, National Cancer Center, Goyang-si, Gyeonggi-do, Korea.

This study was supported by a grant from the National R\&D Program for Cancer Control, Ministry of Health \& Welfare, Republic of Korea (1120300); the Korea Healthcare Technology R\&D Projects, Ministry for Health, Welfare \& Family Affairs (A112028); and the Research Center Program of IBS (Institute for Basic Science) in Korea.

Please address correspondence to Seung Hong Choi, MD, PhD, Department of Radiology, Seoul National University College of Medicine, Center for Nanoparticle Research, Institute for Basic Science, and School of Chemical and Biological Engineering, Seoul National University, 28, Yongon-dong, Chongno-gu, Seoul, 110-744, Korea; e-mail: verocay@snuh.org tient survival and quality of life $\mathrm{e}^{1,2}$ complicates interpretation of posttreatment follow-up imaging studies because surgery can alter anatomy and radiation therapy and chemotherapy can result in edema and fibrosis. These posttreatment changes can mimic tumor recurrence, and sometimes it is difficult to distinguish these from residual or recurrent tumor on CT or MR images. ${ }^{3-5}$

DWI is based on the Brownian motion of water protons in the tissue, which is affected by the microstructure of tissue. ${ }^{6}$ Several previous studies support the value of applying DWI in head and neck cancer for the differentiation and characterization of primary tumor, nodal staging, and the prediction of treatment response. ${ }^{6-12}$ In addition, several promising studies have been reported on the usefulness of DWI in the discrimination between recurrent or residual tumor and posttreatment changes. ${ }^{12-14}$ These studies have demonstrated that performing DWI and mea-

- Indicates open access to non-subscribers at www.ajnr.org

http://dx.doi.org/10.3174/ajnr.A3603

AJNR Am J Neuroradiol 34:2343-48 Dec 2013 www.ajnr.org 
suring the ADC values may enable differentiation of residual or recurrent tumor from posttreatment changes.

In recent years, high $b$-value $\left(b>1000 \mathrm{~s} / \mathrm{mm}^{2}\right.$ ) DWI was introduced along with improvements in MR imaging gradient technology. These high b-value techniques have demonstrated promising results in brain imaging compared with the standard b-value $\left(b=1000 \mathrm{~s} / \mathrm{mm}^{2}\right)$ DWI. ${ }^{15-17}$ In head and neck cancer, a previous study introduced a ratio of the ADC values from high b-value and standard b-value DWI and suggested that it correlates with the maximal standardized uptake value from FDG-PET. ${ }^{18}$ Another published study revealed that high b-value DWI is helpful in the differentiation of histologic grades in HNSCC. ${ }^{19}$

The aim of our present study was to evaluate the additional role and diagnostic performance of high b-value $\left(b=2000 \mathrm{~s} / \mathrm{mm}^{2}\right)$ DWI compared with standard b-value $\left(b=1000 \mathrm{~s} / \mathrm{mm}^{2}\right)$ DWI, and the ratio of $\mathrm{ADC}$ values from high and standard $\mathrm{b}$-values for the differentiation between recurrent tumor and posttreatment changes after treatment of HSNCC.

\section{MATERIALS AND METHODS Study Population}

Our hospital institutional review board approved this retrospective study, and the requirement for informed consent was waived. A total of 1331 patients with head and neck cancer underwent head and neck MR imaging in our institution between January 2010 and February 2012. Among them were 351 patients with pathologically confirmed HNSCC. After retrospectively reviewing the electronic medical records, we included 56 patients matching these inclusion criteria: 1) the patient underwent MR imaging with standard and high b-value DWI after treatment of HNSCC; 2) the term between the end of treatment and posttreatment imaging was longer than 6 weeks, to avoid very early posttreatment changes; 3) there was newly developed or increased enhancing portion on postcontrast T1-weighted images where recurrence was highly suspected or indeterminate; and 4) the lesion was large enough to measure on MR imaging (diameter $\geq 5$ $\mathrm{mm}$ ). A total of 23 patients were further excluded from our study population because of degradation of image quality (eg, susceptibility artifacts that distort the area of concern partly or completely) $(n=15)$, incomplete medical history because of loss to follow-up $(n=7)$, and a history of additional malignant disease outside of the head and neck area $(n=1)$. Finally, we included 33 patients (18 men, 15 women; mean age, 60.2 years; age range, $30-78$ years). The primary tumor locations were the oral cavity $(n=16)$, oropharynx $(n=4)$, sinonasal cavity $(n=5)$, nasopharynx $(n=3)$, hypopharynx $(n=2)$, and external auditory canal $(n=3)$. Various surgical procedures or radiation therapy techniques were performed according to the disease extent and location, with the following treatments: surgery alone $(n=9)$; both chemotherapy and radiation therapy $(n=7)$; surgery and postoperative radiation therapy $(n=13)$; and a combination of chemotherapy, surgery, and radiation therapy $(n=4)$. In our institution, most of the patients treated for head and neck cancer are monitored with MR imaging routinely. Thirteen patients underwent MR imaging earlier than the scheduled date because of clinical suspicion of recurrence (eg, palpable mass or visible lesion on endoscopy; tumor recurrence in 12 patients, posttreatment changes in 1 patient). MR imaging was obtained in 1 patient because of a visible mass at the oral cavity on physical examination; this was followed by MR imaging for 2 years without change, suggesting posttreatment change. All other patients underwent MR imaging as a routine follow-up technique.

\section{Determination of Recurrent Tumor vs Posttreatment Changes}

Recurrent tumor and posttreatment changes were differentiated with clinical or histopathologic characterization as follows:

Histopathologic Diagnosis. We obtained the pathologic diagnosis by reviewing the institution electronic medical records. The institution pathologists, who had at least fellowship training in reading head and neck pathologic changes, made these pathology reports. Histopathologic evaluation was performed in 19 cases; 17 and 2 were confirmed as recurrent tumor and posttreatment changes, respectively. Pathologic diagnoses for those 2 patients were chronic hyperplastic candidiasis and chronic active inflammation, and these patients had no evidence of recurrence during subsequent follow-up at 22 months and at 15 months, respectively.

Clinical Diagnosis. In patients without histopathologic evaluation during follow-up, tumor recurrence was defined by clinical criteria. In 3 cases, recurrent tumors were clinically determined based on growth of an enhancing lesion by at least $20 \%$ or more on the subsequent follow-up image. Posttreatment lesions $(n=11)$ were clinically defined as no change or a decrease in size of the enhancing lesion and no other evidence of recurrence during at least 1 year of follow-up (mean follow-up time, 24 months; range, 15-39 months).

\section{MR Imaging Acquisition}

All patients underwent MR imaging by use of a 1.5T MR imaging system (Signa Excite, HDx or HDxt; GE Healthcare, Milwaukee, Wisconsin) with an 8-channel head and neck coil. A transverse T1-weighted spin-echo sequence was performed with the following parameters: TR range, 550-560 ms; TE range, 10-12 ms; 30-36 sections; section thickness, $4 \mathrm{~mm}$; intersection gap, 1.2 mm; FOV, $220 \times 220$ mm; matrix, $320 \times 192$; acquired signal, 1 ; and pixel resolution, $0.7 \times 1.1 \times 4.0 \mathrm{~mm}$. The contrast-enhanced transverse T1-weighted spin-echo sequences with fat suppression were also acquired after the intravenous injection of $0.1 \mathrm{mmol} / \mathrm{kg}$ of gadopentetate dimeglumine (Magnevist; Bayer Schering Pharma, Berlin, Germany). Additional coronal and sagittal T1weighted sequences were performed with identical imaging parameters after administration of contrast agent.

The single-shot echo-planar DWI was obtained in the transverse plane before contrast material injection at both the standard b-value $\left(b=0\right.$ and $\left.1000 \mathrm{~s} / \mathrm{mm}^{2}\right)$ and high b-value $\left(b=0\right.$ and $\left.2000 \mathrm{~s} / \mathrm{mm}^{2}\right)$ with the following parameters: TR range, $8000-10,000 \mathrm{~ms}$ and TE range, $61.6-77.6 \mathrm{~ms}$ (at $b=1000 \mathrm{~s} / \mathrm{mm}^{2}$ ); TR range, $9325-12,000 \mathrm{~ms}$ and TE range, $73.8-90.4 \mathrm{~ms}$ (at $b=2000 \mathrm{~s} / \mathrm{mm}^{2}$ ); $30-45$ sections; section thickness, $4 \mathrm{~mm}$; intersection gap, $1.2 \mathrm{~mm}$; bandwidth, 1953 $\mathrm{Hz} /$ pixel; FOV , $240 \times 240 \mathrm{~mm}$; matrix, $160 \times 160$; acquired signal, 2 ; and pixel resolution, $1.5 \times 1.5 \times 4.0 \mathrm{~mm}$. DWI data were acquired in 3 orthogonal directions and combined into a trace image. The average durations of DWI at $b=0$ and $1000 \mathrm{~s} / \mathrm{mm}^{2}$ and $b=0$ and 2000 $\mathrm{s} / \mathrm{mm}^{2}$ were $1 \mathrm{~min} 23 \mathrm{~s}$ and $2 \mathrm{~min} 50 \mathrm{~s}$, respectively.

The corresponding ADC maps were automatically derived from the following equation on the Advantage workstation (GE Healthcare): $\mathrm{ADC}=-\ln [\mathrm{S}(\mathrm{b}) / \mathrm{S}(0)] / \mathrm{b}$, where $\mathrm{b}$ is the diffusion- 
Table 1: Comparison of demographic and clinicopathologic features between recurrent tumor group and posttreatment changes group

\begin{tabular}{lccc}
\hline & \multicolumn{2}{c}{ Patient Group } & \\
\cline { 2 - 3 } \multicolumn{1}{c}{ Characteristic } & $\begin{array}{c}\text { Recurrent } \\
\text { Tumor }\end{array}$ & $\begin{array}{c}\text { Posttreatment } \\
\text { Changes }\end{array}$ & P Value \\
\hline Mean age (y) & 58.2 (range, 30-77) & 63.2 (range, 44-78) & .288 \\
Sex (M:F) & $4: 9$ & $14: 6$ & $.038^{\mathrm{a}}$ \\
Clinical suspicion of tumor recurrence ${ }^{\mathrm{b}}$ & $60 \%(12)$ & $0.7 \%(1)$ & $.003^{\mathrm{a}}$ \\
Mean ROI size $\left(\mathrm{mm}^{2}\right)$ & $170.59 \pm 190.68$ & $152.15 \pm 203.65$ & .773 \\
Interval between treatment and & $15.1 \pm 16.0$ & $10.4 \pm 9.5$ & .342 \\
$\quad$ imaging (mo) & & & \\
\hline a Fisher exact test. & & & \\
b Number of patients in parentheses. & & &
\end{tabular}

Table 2: ADC values of the newly developed or increased enhancing portion and deep cervical muscles

\begin{tabular}{cccc}
\hline & \multicolumn{2}{c}{ Value (Mean \pm SD) } & \\
\cline { 2 - 3 } & $\begin{array}{c}\text { Recurrent } \\
\text { Tumor }\end{array}$ & $\begin{array}{c}\text { Posttreatment } \\
\text { Changes }\end{array}$ & $P$ Value $^{\mathbf{a}}$ \\
\hline Newly detected or increased enhancing lesion & & & \\
$\mathrm{ADC}_{1000}\left(10^{-3} \mathrm{~mm}^{2} / \mathrm{s}\right)$ & $1.205 \pm 0.244$ & $1.649 \pm 0.319$ & $<.001$ \\
$\mathrm{ADC}_{2000}\left(10^{-3} \mathrm{~mm}^{2} / \mathrm{s}\right)$ & $0.878 \pm 0.153$ & $0.940 \pm 0.235$ & .365 \\
$\mathrm{ADC}_{\text {ratio }}(\%)$ & $73.5 \pm 7.2$ & $56.9 \pm 8.8$ & $<.001$ \\
Deep cervical muscles & & & \\
$\mathrm{ADC}_{1000}\left(10^{-3} \mathrm{~mm}^{2} / \mathrm{s}\right)$ & $1.338 \pm 0.103$ & $1.301 \pm 0.133$ & .371 \\
$\mathrm{ADC}_{2000}\left(10^{-3} \mathrm{~mm}^{2} / \mathrm{s}\right)$ & $0.722 \pm 0.128$ & $0.724 \pm 0.157$ & .967 \\
$\mathrm{ADC}_{\text {ratio }}(\%)$ & $53.9 \pm 8.1$ & $55.2 \pm 7.8$ & .643 \\
\hline
\end{tabular}

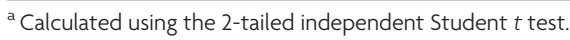

weighting factor $\left(b=1000\right.$ or $\left.2000 \mathrm{~s} / \mathrm{mm}^{2}\right)$, and $\mathrm{S}(\mathrm{b})$ and $\mathrm{S}(0)$ are the signal intensities with and without diffusion-sensitizing gradients, respectively.

\section{Image Analysis}

MR images were reviewed on a PACS workstation monitor ( $\mathrm{m}$ view 5.4; Infinitt, Seoul, Korea). ADC ratio $\left(\mathrm{ADC}_{\text {ratio }}=\mathrm{ADC}_{2000} /\right.$ $\mathrm{ADC}_{1000} \times 100$, where $\mathrm{ADC}_{1000}$ and $\mathrm{ADC}_{2000}$ are the $\mathrm{ADC}$ values of the DWI obtained with $b=0$ and $1000 \mathrm{~s} / \mathrm{mm}^{2}$, and $b=0$ and $2000 \mathrm{~s} / \mathrm{mm}^{2}$, respectively) maps were generated by use of pixelby-pixel computation of ADC maps generated with in-housedeveloped software.

The images were reviewed by consensus between 2 investigators (I.H. and S.H.C. with 2 years and 10 years of experience in interpreting head and neck MR images, respectively), in which the investigators placed ROIs on the axial $\mathrm{ADC}_{1000}$ maps with references of contrast-enhanced T1-weighted images obtained in 3 orthogonal planes. At the time of the interpretation session, the investigators were blinded to the final pathologic or clinical results. The ROIs were drawn on the most representative section of the ADC map, in which the size of the tumor was the largest or the conspicuity of the lesion was highest. The boundary of the ROI encompassed all of the visible tumor on that section of the ADC map corresponding to the contrast-enhanced T1-weighted images, but any necrotic portion and normal osseous structures were avoided to the fullest extent possible. Subsequently, the ROIs were copied onto the corresponding $\mathrm{ADC}_{2000}$ and $\mathrm{ADC}_{\text {ratio }}$ maps, respectively. The size of each ROI was also recorded.

In addition, ROI measurement from the deep cervical muscles was included for comparison as an internal control of normal soft tissue. On a section encompassing the largest areas of the deep cervical muscles, a large circular ROI was drawn on the $\mathrm{ADC}_{1000}$ maps and was subsequently copied to the corresponding $\mathrm{ADC}_{2000}$ and $\mathrm{ADC}_{\text {ratio }}$ maps, respectively.

\section{Statistical Analysis}

All statistical analyses were performed with SPSS Statistics 19.0 for Windows (IBM, Armonk, New York). For all statistical analyses, a 2-tailed $P$ value $<.05$ was considered to indicate a statistically significant difference. The 2-tailed independent Student $t$ test was used to compare the clinicopathologic characteristics (eg, age, mean interval from completion of therapy to follow-up imaging, and the ROI size) and mean ADC values between the group with recurrent tumor and the group with posttreatment changes. In addition, the 2-tailed paired Student $t$ test was used to assess the differences between the newly developed enhancing lesion and deep cervical muscles in each group. Multivariate binary logistic regression was performed to assess the most independently differentiating variable between $\mathrm{ADC}_{1000}$, $\mathrm{ADC}_{2000}$, and $\mathrm{ADC}_{\text {ratio. }}$. Furthermore, a receiver operating characteristic curve was drawn to investigate the optimal cutoff values for the parameters with statistical significance, of which sensitivity, specificity, and accuracy were also calculated.

\section{RESULTS}

\section{Clinicopathologic Characteristics}

In our study population, recurrent tumor was found in 20 patients and posttreatment changes were found in 13 patients. There were more male patients in the recurrent tumor group $(\mathrm{M}: \mathrm{F}=14: 6)$ vs the posttreatment changes group ( $\mathrm{M}: \mathrm{F}=4: 9)$. In the recurrent tumor group, MR imaging was obtained mainly because of clinical suspicion of recurrence, whereas MR imaging was mostly performed in a routine follow-up manner in the group with posttreatment changes (Table 1). Otherwise, no significant difference was observed in mean age, mean ROI size, and mean interval from completion of therapy to follow-up imaging between the recurrent tumor group and the group with posttreatment changes (Table 1). The mean imaging follow-up time of the group with posttreatment changes was 23 months, and no patient had recurrence during the follow-up period.

\section{Comparison of $A D C_{1000}, A D C_{2000}$, and $A D C_{\text {ratio }}$ between Patients with Recurrent Tumor and Patients with Posttreatment Changes}

Table 2 and Fig 1 summarize the mean $\mathrm{ADC}_{1000}, \mathrm{ADC}_{2000}$, and $\mathrm{ADC}_{\text {ratio }}$ of the focal enhancing lesion vs the deep cervical muscles of the 2 groups. The mean $\mathrm{ADC}_{1000}$ in the recurrent tumor group was significantly lower than that in the posttreatment change group ( 1.205 vs $1.649 \times 10^{-3} \mathrm{~mm}^{2} / \mathrm{s}$, respectively; $\left.P<.001\right)$. Similarly, the mean $\mathrm{ADC}_{2000}$ also showed a lower value in the recurrent tumor group vs the posttreatment changes group, but without a statistically significant difference $(0.878$ vs $0.940 \times$ $\left.10^{-3} \mathrm{~mm}^{2} / \mathrm{s} ; P=.365\right)$. The mean $\mathrm{ADC}_{\text {ratio }}$ of the recurrent tu- 

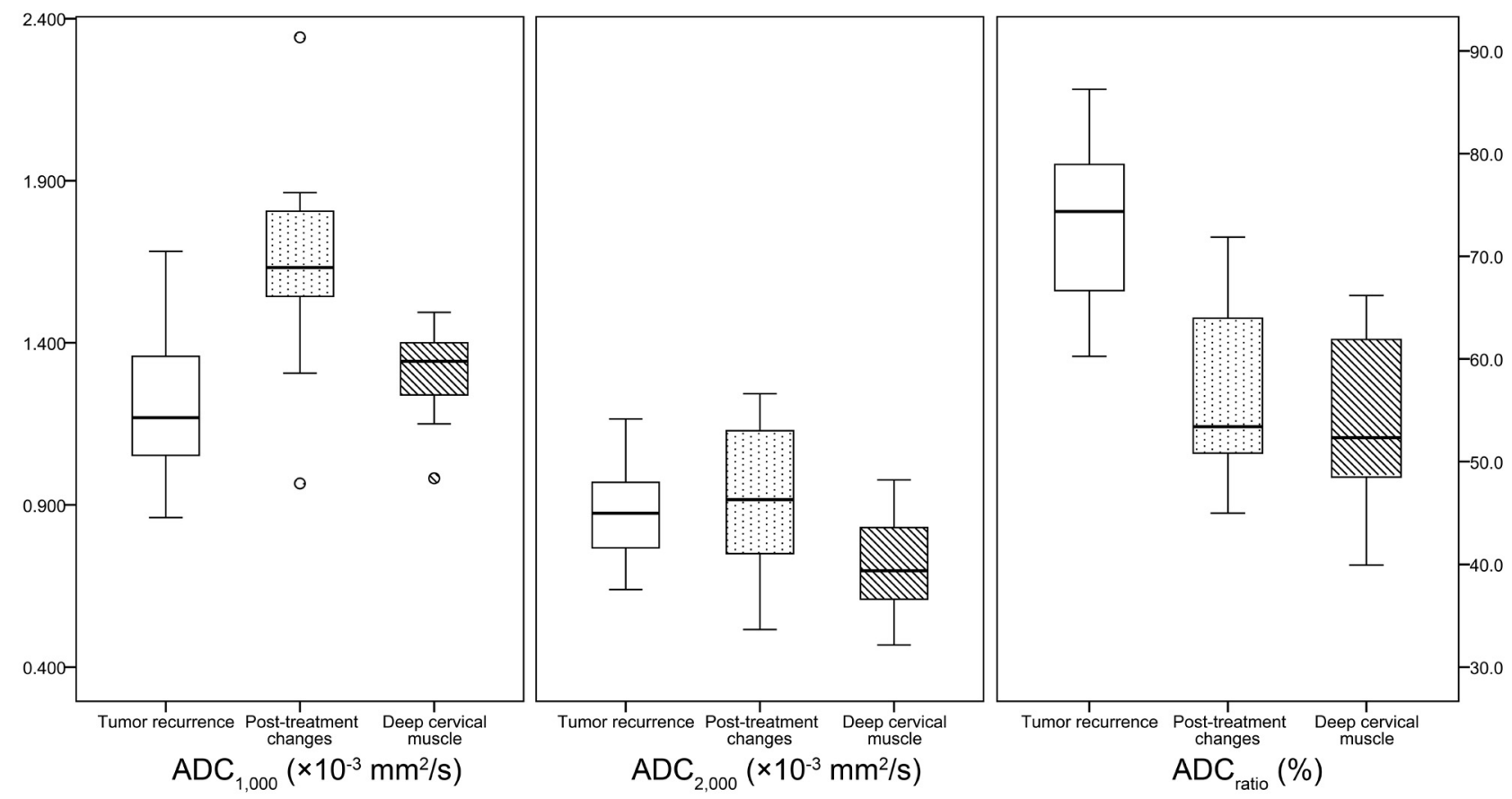

FIG 1. Box-and-whisker plots of the $A D C$ values at the standard b-value $\left(A D C_{1000}\right)$, high b-value $\left(A D C_{2000}\right)$, and the $A D C$ ratio $\left(A D C_{\text {ratio }}\right)$ in the newly detected enhancing lesion on the postcontrast T1-weighted image and deep cervical muscle (horizontal line = median values, bottom of the box: 25 th percentile, top of the box $=75$ th percentile, whiskers $=$ smallest or largest values except outliers, small circle $=$ outliers).
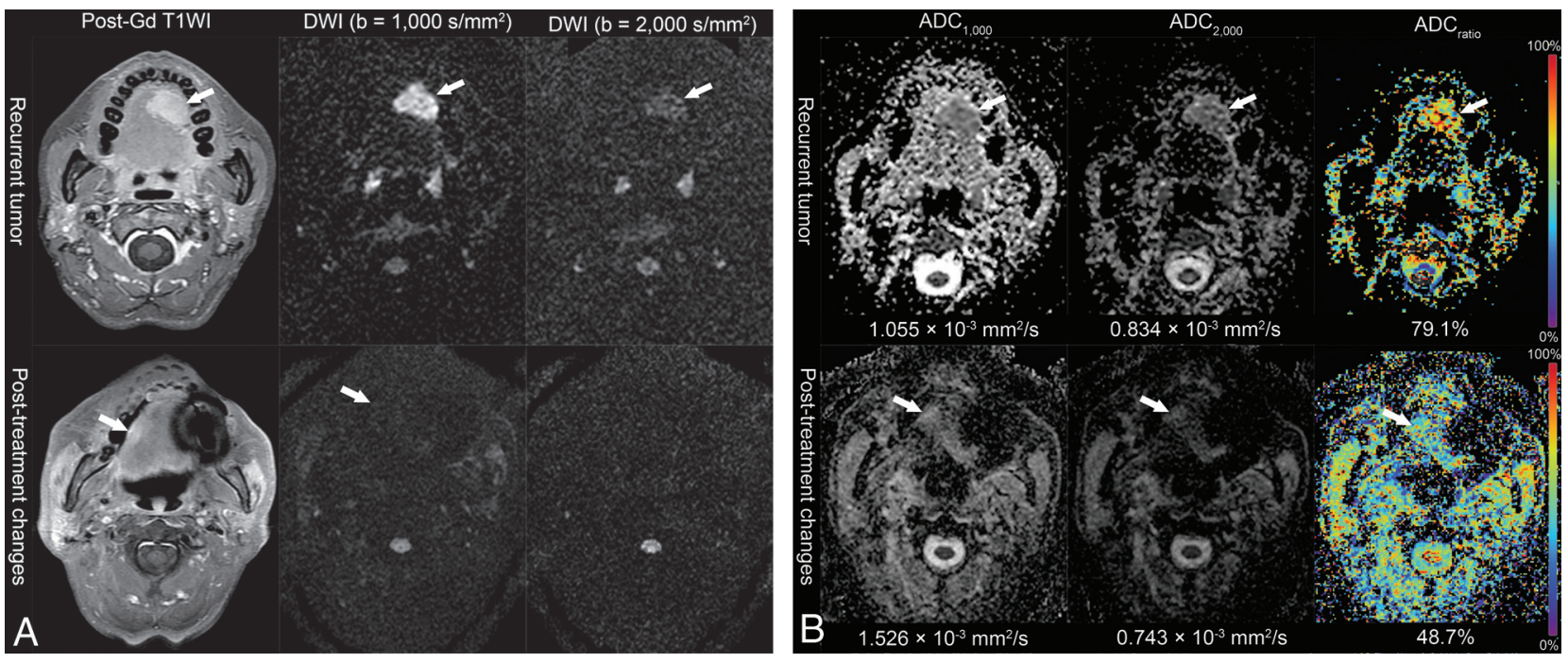

FIG 2. Representative MR images of the recurrent tumor (37-year-old woman, status post left partial glossectomy) and posttreatment changes (63-year-old woman, status post right hemiglossectomy and postoperative radiation therapy) from treated squamous cell carcinoma of the tongue. A, Postcontrast T1-weighted images and DWI with standard and high b-values. The recurrent tumor shows high signal intensity on the DWI in both standard and high b-values. In contrast, the signal intensity of posttreatment changes on the high-b-value DWI is not increased. $B$, Corresponding ADC maps show lower ADC values in the recurrent tumor than those in the posttreatment changes on the standard b-value DWI. Color-coded $A D C_{\text {ratio }}$ maps demonstrate that the $A D C_{\text {ratio }}$ is much increased in the recurrent tumor.

mor group was significantly higher than that of the posttreatment changes group $(73.5 \%$ vs $56.9 \%$, respectively; $P<.001)$.

No significant difference was observed between the recurrent tumor group and the posttreatment changes group in the mean $\mathrm{ADC}_{1000}, \mathrm{ADC}_{2000}$, and $\mathrm{ADC}_{\text {ratio }}$ of the deep cervical muscles (Table 2).

The mean $\mathrm{ADC}_{\text {ratio }}$ of recurrent tumor was significantly higher than that of cervical muscles $(73.5 \%$ vs $53.9 \%$; $P<.001)$. However, the mean $\mathrm{ADC}_{\text {ratio }}$ of enhancing lesion because of post- treatment changes was not significantly different from that of deep cervical muscles ( $56.9 \%$ vs $55.2 \% ; P=.553$ ). Figure 2 shows representative MR images of the recurrent tumor group and the posttreatment changes group, respectively.

\section{Multivariate Logistic Regression Analysis}

The $\mathrm{ADC}_{1000}$ and $\mathrm{ADC}_{\text {ratio }}$ were significantly different variables to differentiate between recurrent tumor and posttreatment changes by the independent Student $t$ test. Multivariate logistic 
Table 3: Diagnostic performances of the $A D C_{1000}$ and $A D C_{\text {ratio }}$

\begin{tabular}{|c|c|c|c|c|c|c|}
\hline & Cutoff Value $^{a}$ & Sensitivity (\%) & Specificity (\%) & PPV (\%) & NPV (\%) & Accuracy (\%) \\
\hline $\mathrm{ADC}_{1000}$ & $1.460 \times 10^{-3} \mathrm{~mm}^{2} / \mathrm{s}$ & $85.0(17 / 20)$ & $84.6(11 / 13)$ & $89.5(17 / 19)$ & $78.6(11 / 14)$ & $84.8(28 / 33)$ \\
\hline$A D C_{\text {ratio }}$ & $62.6 \%$ & $95.0(19 / 20)$ & $69.2(9 / 13)$ & $69.6(16 / 23)$ & $90.0(9 / 10)$ & $84.8(28 / 33)$ \\
\hline
\end{tabular}

Note:-Raw data are in parentheses. NPV indicates negative predictive value; PPV, positive predictive value.

${ }^{a}$ Receiver operating characteristic curves were drawn to find the optimal cutoff values for the $A D C_{1000}$ and $A D C_{\text {ratio. }}$

regression analysis with the $\mathrm{ADC}_{1000}$ and $\mathrm{ADC}_{\text {ratio }}$ as independent variables was constructed. The $\mathrm{ADC}_{\text {ratio }}$ was the most independently differentiating variable $(P=.024)$, whereas the $\mathrm{ADC}_{1000}$ was marginally insignificant $(P=.051)$.

\section{Optimal Cutoff Values and Diagnostic Performances}

Receiver operating characteristic curves were drawn to find the opti-

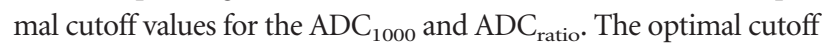
value for the $\mathrm{ADC}_{1000}$ was $1.460 \times 10^{-3} \mathrm{~mm}^{2} / \mathrm{s}$. The sensitivity, specificity, and accuracy were $85.0 \%$ (17/20), 84.6\% (11/13), and $84.8 \%$ (28/33), respectively. For the $\mathrm{ADC}_{\text {ratio }}$, the optimal cutoff value was $62.6 \%$, and the sensitivity, specificity, and accuracy were 95.0\% (19/20), 69.2\% (9/13), and 84.8\% (28/33), respectively. The summary of the diagnostic performance of each value is listed in Table 3 .

\section{DISCUSSION}

Our results demonstrate that the ADC value derived from the standard b-value DWI $\left(b=1000 \mathrm{~s} / \mathrm{mm}^{2}\right)$ had a similar diagnostic performance compared with a previous study, and that the mean $\mathrm{ADC}_{1000}$ in the posttreatment changes group was significantly higher than that of the recurrent tumor group. ${ }^{13}$ The optimal cutoff value for the $\mathrm{ADC}_{1000}$ to distinguish between recurrent tumor and postoperative changes $\left(1.460 \times 10^{-3} \mathrm{~mm}^{2} / \mathrm{s}\right)$ also correlated with a previous study $\left(1.30 \times 10^{-3} \mathrm{~mm}^{2} / \mathrm{s}\right) .{ }^{13}$ These reproducible findings support the use of the standard b-value DWI on posttreatment follow-up imaging of HNSCC. On the other hand, the mean $\mathrm{ADC}_{2000}$ itself was not significantly different between the 2 groups and did not have an additional diagnostic benefit. However, we did observe a significant difference in the mean $\mathrm{ADC}_{\text {ratio }}$ between the recurrent tumor group and the posttreatment changes group $(73.5 \pm 7.2 \%$ vs $56.9 \pm 8.8 \%$, respectively); multivariate logistic regression analysis showed that the $\mathrm{ADC}_{\text {ratio }}$ vs the $\mathrm{ADC}_{1000}$ was more useful for differentiating between the 2 groups.

The ADC value has been known to decrease when the b-value increases beyond $1000 \mathrm{~s} / \mathrm{mm}^{2}$, according to several previous reports. $^{20-22}$ The decrease in the observed ADC with an increasing b-value could be explained by the decay of biexponential signal intensity. In a human brain model, fast and slow diffusion components have been described. ${ }^{20,22}$ Fast diffusion components are the main source of signal at a relatively low b-value, whereas the signal intensity is dominated by the slow diffusion component at a high b-value. ${ }^{23}$ Increased cellularity in recurrent tumor leads to an increase in the intracellular water component, whereas posttreatment changes are composed of edema and inflammatory changes, increasing the proportion of easily diffusible extracellular water content. ${ }^{6,13}$ Although the intracellular and extracellular water components are not exactly equal to the slow and fast diffusion components, respectively, they are considered corresponding components. ${ }^{20,24}$ To evaluate the fast and slow diffusion components, DWI with multiple b-values has been studied with a biexponential fitting. ${ }^{25}$ In our study, we calculated $2 \mathrm{ADC}$ values with a monoexponential model with 2 different b-values, and we adopted the $\mathrm{ADC}_{\text {ratio }}$ as an alternative biomarker that represents the composition of the fast and slow diffusion components. Choi et $\mathrm{al}^{18}$ hypothesized that by increasing the b-value from 1000 $\mathrm{s} / \mathrm{mm}^{2}$ to $2000 \mathrm{~s} / \mathrm{mm}^{2}$, the ADC value would have a more substantial decrease in the fast diffusion component. As a result, the higher $\mathrm{ADC}_{\text {ratio }}$ means that it contains more of the slow diffusion component and represents higher cellularity. ${ }^{18}$ Therefore, our results show that the mean $\mathrm{ADC}_{\text {ratio }}$ was much higher in the recurrent tumor group vs the posttreatment changes group.

Although the mean $\mathrm{ADC}_{2000}$ also showed a lower value in the recurrent tumor compared with posttreatment changes, it was not statistically different between the 2 groups. A possible explanation is that the relative decrease of $\mathrm{ADC}_{1000}$ to $\mathrm{ADC}_{2000}$ was higher in the posttreatment changes group; therefore, the final $\mathrm{ADC}_{2000}$ of the recurrent tumor group was similar to that of the posttreatment changes group. The differences between the $\mathrm{ADC}_{1000}$ and $\mathrm{ADC}_{2000}$ also could be influenced by different imaging parameters. However, Ogura et $\mathrm{al}^{26}$ reported that a long TR $(>6000 \mathrm{~ms})$ and short TE $(<100 \mathrm{~ms})$ did not significantly influence the ADC values. Therefore, the influence of different imaging parameters was thought to be negligible in our study.

For comparison, we also investigated the ADC values from the deep cervical muscles as a normal soft tissue. With the increase in the b-value from 1000 to $2000 \mathrm{~s} / \mathrm{mm}^{2}$, the ADC value was also substantially decreased in muscle. The mean ADC ratio of the recurrent tumor group was significantly higher than that of the deep cervical muscles, which might prove beneficial for the detection of recurrent tumor by visual inspection in the $\mathrm{ADC}_{\text {ratio }}$ maps.

The diagnostic yields of both $\mathrm{ADC}_{\text {ratio }}$ and $\mathrm{ADC}_{1000}$ in our present study was lower than those of the study by Abdel Razek et $\mathrm{al}^{13}{ }^{13}$ in which they used only $\mathrm{ADC}_{1000}$ maps.. We believe that this finding might be the result of differences in study populations. The minimal size of the lesions was $1.5 \mathrm{~cm}$ in diameter in the study by Abdel Razek et al, ${ }^{13}$ whereas our study included smaller lesions (eg, $5 \mathrm{~mm}$ ).

In our study, 15 patients were excluded because of MR imaging artifacts or poor visualization of the lesion, and the proportion of artifacts in eligible patients was relatively high $(26.8 \%)$. Although we optimized scanning parameters to reduce artifacts and maximize the signal-to-noise ratio, we found that the intrinsic limitations of single-shot echo-planar DWI in head and neck imaging (eg, heterogeneity of the tissue, a very low acquirable signal, movements, air-tissue boundaries, and surgical materials) were still challenging in interpreting the DWI. ${ }^{27}$ To overcome the drawbacks of DWI, additional localized coverage imaging or zonally magnified oblique multisection (ZOOM; Siemens, Erlangen, Germany) echo-planar imaging could be performed. ${ }^{28}$

Our study had some limitations. One limitation was that we enrolled a small number of patients from a single center and performed retrospective analysis, which could lead to selection bias. 
We tried to include all patients who met the inclusion criteria to minimize selection bias. In addition, we included HNSCC with various locations, treatment modalities, and intervals between last treatment and imaging, and this heterogeneity could limit the generalizability of our results. Although tumor location is related to prognosis, ${ }^{29}$ we believed that any significant impact of tumor location relative to ADC values was unlikely.

Another limitation of our present study was that there were patients for whom we did not have histopathologic confirmation. Therefore, exact correlation of the $\mathrm{ADC}$ value or $\mathrm{ADC}_{\text {ratio }}$ with histopathologic changes was limited, especially for the posttreatment changes group. In clinical settings, it is common practice to follow patients with complementary imaging modalities, such as FDG-PET, to ensure that the enhancing lesion identified by MR imaging is metabolically active before a biopsy is performed, ${ }^{30}$ but this was not possible in the context of our study.

\section{CONCLUSIONS}

We suggest that the $\mathrm{ADC}_{\text {ratio }}$ calculated from $\mathrm{ADC}_{1000}$ and $\mathrm{ADC}_{2000}$ is a promising value to differentiate between recurrent tumor and posttreatment changes in HNSCC and may be marginally more useful than the $\mathrm{ADC}_{1000}$ alone. High b-value DWI of the head and neck region is technically feasible and requires a relatively short additional scan time; therefore, high b-value DWI could be added to the posttreatment routine follow-up MR imaging to provide additional potentially helpful information in the detection of recurrent HNSCC.

Disclosures: Seung Hong Choi-RELATED: Grant: A grant from the National R\&D Program for Cancer Control, Ministry of Health \& Welfare, Republic of Korea (1120300), ${ }^{*}$ the Korea Healthcare Technology R\&D Projects, Ministry for Health, Welfare \& Family Affairs (A112028).* *Money paid to institution.

\section{REFERENCES}

1. El-Deiry M, Funk GF, Nalwa S, et al. Long-term quality of life for surgical and nonsurgical treatment of head and neck cancer. Arch Otolaryngol Head Neck Surg 2005;131:879-85

2. Ang KK, Harris J, Garden AS, et al. Concomitant boost radiation plus concurrent cisplatin for advanced head and neck carcinomas: radiation therapy oncology group phase II trial 99-14. J Clin Oncol 2005;23:3008-15

3. Zbaren P, Caversaccio M, Thoeny HC, et al. Radionecrosis or tumor recurrence after radiation of laryngeal and hypopharyngeal carcinomas. Otolaryngol Head Neck Surg 2006;135:838-43

4. Nomayr A, Lell M, Sweeney R, et al. MRI appearance of radiationinduced changes of normal cervical tissues. Eur Radiol 2001;11: 1807-17

5. Offiah C, Hall E. Post-treatment imaging appearances in head and neck cancer patients. Clin Radiol 2011;66:13-24

6. Wang J, Takashima S, Takayama F, et al. Head and neck lesions: characterization with diffusion-weighted echo-planar MR imaging. Radiology 2001;220:621-30

7. Srinivasan A, Dvorak R, Perni K, et al. Differentiation of benign and malignant pathology in the head and neck using $3 \mathrm{~T}$ apparent diffusion coefficient values: early experience. AJNR Am J Neuroradiol 2008;29:40-44

8. Maeda M, Kato H, Sakuma H, et al. Usefulness of the apparent diffusion coefficient in line scan diffusion-weighted imaging for distinguishing between squamous cell carcinomas and malignant lymphomas of the head and neck. AJNR Am J Neuroradiol 2005;26:1186-92

9. Sumi M, Sakihama N, Sumi T, et al. Discrimination of metastatic cervical lymph nodes with diffusion-weighted MR imaging in patients with head and neck cancer. AJNR Am J Neuroradiol 2003;24:1627-34

10. Vandecaveye V, De Keyzer F, Vander Poorten V, et al. Head and neck squamous cell carcinoma: value of diffusion-weighted MR imaging for nodal staging. Radiology 2009;251:134-46

11. Kim S, Loevner L, Quon H, et al. Diffusion-weighted magnetic resonance imaging for predicting and detecting early response to chemoradiation therapy of squamous cell carcinomas of the head and neck. Clin Cancer Res 2009;15:986-94

12. King AD, Mo FK, Yu KH, et al. Squamous cell carcinoma of the head and neck: diffusion-weighted MR imaging for prediction and monitoring of treatment response. Eur Radiol 2010;20:2213-20

13. Abdel Razek AA, Kandeel AY, Soliman N, et al. Role of diffusionweighted echo-planar MR imaging in differentiation of residual or recurrent head and neck tumors and posttreatment changes. AJNR Am J Neuroradiol 2007;28:1146-52

14. Vandecaveye V, De Keyzer F, Nuyts S, et al. Detection of head and neck squamous cell carcinoma with diffusion weighted MRI after (chemo)radiotherapy: correlation between radiologic and histopathologic findings. Int J Radiat Oncol Biol Phys 2007;67:960-71

15. Seo HS, Chang KH, Na DG, et al. High b-value diffusion ( $\mathbf{b}=\mathbf{3 0 0 0}$ $\mathrm{s} / \mathrm{mm} 2$ ) MR imaging in cerebral gliomas at 3T: visual and quantitative comparisons with $\mathbf{b}=1000 \mathrm{~s} / \mathrm{mm} 2$. AJNR Am J Neuroradiol 2008;29:458-63

16. Kang Y, Choi SH, Kim YJ, et al. Gliomas: histogram analysis of apparent diffusion coefficient maps with standard- or high-b-value diffusion-weighted MR imaging-correlation with tumor grade. Radiology 2011;261:882-90

17. Purroy F, Begue R, Quilez A, et al. Contribution of high-b-value diffusion-weighted imaging in determination of brain ischemia in transient ischemic attack patients. J Neuroimaging 2013;23:33-38

18. Choi SH, Paeng JC, Sohn CH, et al. Correlation of 18F-FDG uptake with apparent diffusion coefficient ratio measured on standard and high b value diffusion MRI in head and neck cancer. J Nucl Med 2011;52:1056-62

19. Yun TJ, Kim JH, Kim KH, et al. Head and neck squamous cell carcinoma: Differentiation of histologic grade with standard- and high-b-value diffusion-weighted MRI. Head Neck 2013;35:626-31

20. Clark CA, Le Bihan D. Water diffusion compartmentation and anisotropy at high b values in the human brain. Magn Reson Med 2000;44:852-59

21. DeLano MC, Cooper TG, Siebert JE, et al. High-b-value diffusionweighted MR imaging of adult brain: image contrast and apparent diffusion coefficient map features. AJNR Am J Neuroradiol 2000;21:1830-36

22. Brugieres $\mathrm{P}$, Thomas $\mathrm{P}$, Maraval A, et al. Water diffusion compartmentation at high $\mathbf{b}$ values in ischemic human brain. AJNR Am J Neuroradiol 2004;25:692-98

23. Maier SE, Bogner P, Bajzik G, et al. Normal brain and brain tumor: multicomponent apparent diffusion coefficient line scan imaging. Radiology 2001;219:842-49

24. Sehy JV, Ackerman JJ, Neil JJ. Evidence that both fast and slow water ADC components arise from intracellular space. Magn Reson Med 2002;48:765-70

25. Roth Y, Tichler T, Kostenich G, et al. High-b-value diffusion-weighted MR imaging for pretreatment prediction and early monitoring of tumor response to therapy in mice. Radiology 2004;232:685-92

26. Ogura A, Hayakawa K, Miyati T, et al. Imaging parameter effects in apparent diffusion coefficient determination of magnetic resonance imaging. Eur J Radiol 2011;77:185-88

27. Thoeny HC, De Keyzer F, King AD. Diffusion-weighted MR imaging in the head and neck. Radiology 2012;263:19-32

28. Wheeler-Kingshott CA, Trip SA, Symms MR, et al. In vivo diffusion tensor imaging of the human optic nerve: pilot study in normal controls. Magn Reson Med 2006;56:446-51

29. Mehanna H, West CM, Nutting C, et al. Head and neck cancer-Part 2: Treatment and prognostic factors. BMJ 2010;341:c4690

30. Kubota K, Yokoyama J, Yamaguchi K, et al. FDG-PET delayed imaging for the detection of head and neck cancer recurrence after radiochemotherapy: comparison with MRI/CT. Eur J Nucl Med Mol Imaging 2004;31:590-95 